\title{
Anticancer effect of metformin on estrogen receptor-positive and tamoxifen-resistant breast cancer cell lines
}

\author{
JINKYOUNG KIM ${ }^{1}$, JIYUN LEE ${ }^{2}$, SOON YOUNG JANG ${ }^{2}$, CHUNGYEUL KIM ${ }^{1}$, YOOJIN CHOI ${ }^{1}$ and AEREE KIM ${ }^{1}$ \\ ${ }^{1}$ Department of Pathology, Korea University Guro Hospital, Guro-gu, Seoul 08308; \\ ${ }^{2}$ Department of Pathology, College of Medicine, Korea University, Seongbuk-gu, Seoul 02841, Republic of Korea
}

Received December 14, 2015; Accepted January 26, 2016

DOI: 10.3892/or.2016.4675

\begin{abstract}
Acquisition of tamoxifen resistance (TR) during anti-estrogenic therapy using tamoxifen is a major obstacle in the treatment of estrogen receptor (ER)-positive breast cancer. As a biguanide derivative, metformin is commonly used to treat type II diabetes. It has recently emerged as a potential anticancer agent. The objective of the present study was to investigate the anticancer activity of metformin in relation to $\mathrm{ER} \alpha$ expression and its signaling pathway in ER $\alpha$-positive MCF-7 and MDA-MB-361 breast cancer cells as well as TR MCF-7 breast cancer cells. Metformin inhibited both protein and mRNA levels of ER $\alpha$ in the presence or absence of estrogen (E2) in the MCF-7, TR MCF-7 and MDA-MB-361 cells. Metformin repressed E2-inducible estrogen response element (ERE) luciferase activity, protein levels and mRNA levels of E2/ER $\alpha$-regulated genes [including c-Myc, cyclin D1, progesterone receptor $(\mathrm{PR})$ and $\mathrm{pS} 2$ ] to a greater degree than tamoxifen, resulting in inhibition of cell proliferation of MCF-7, TR MCF-7 and MDA-MB-361 cells. Collectively, our results suggest that one of the anticancer mechanisms of metformin could be attributable to the repression of expression and transcriptional activity of ER $\alpha$. Metformin may be a good therapeutic agent for treating ER $\alpha$-positive breast cancer by inhibiting the expression and function of ER $\alpha$. In addition, metformin may be useful to treat tamoxifen-resistant breast cancer.
\end{abstract}

\section{Introduction}

Estrogen receptor (ER) is an important prognostic marker and therapeutic target of breast cancer. There are two classes of ER: $\mathrm{ER} \alpha$ and $\mathrm{ER} \beta$ (1). $\mathrm{ER} \alpha$ is predominantly expressed in breast

Correspondence to: Dr Aeree Kim, Department of Pathology, Korea University Guro Hospital, 148 Gurodong-ro, Guro-gu, Seoul 08308, Republic of Korea

E-mail: ark@korea.ac.kr

Key words: estrogen receptor, tamoxifen resistance, metformin, estrogen response element, breast cancer, anti-estrogen therapy ductal epithelial cells. It plays a crucial role in both mammary carcinogenesis and breast cancer progression $(2,3)$. ER $\alpha$ is a member of the nuclear receptor superfamily of transcription factors whose activity is primarily regulated by estrogen (E2) binding. It regulates the transcription of target genes $(4,5)$. ER $\alpha$-positive breast cancer accounts for $70 \%$ of all breast cancer cases. Patients with these tumors are candidates for anti-estrogen therapy after surgical treatment. Such therapy is through blockage of binding of $\mathrm{E} 2 / \mathrm{ER} \alpha$ with selective ER modulators (SERMs) such as tamoxifen or by inhibiting E2 biosynthesis using aromatase inhibitors (AIs) (6). Only 60\% of all ER $\alpha$-positive breast cancers are responsive to tamoxifen. Unfortunately, the majority of these patients who do respond well initially often develop resistance to tamoxifen therapy and have relapse during their clinical courses (7). Although acquisition of tamoxifen resistance (TR) is due to a variety of factors, the mechanisms underlying this phenomenon remain poorly understood.

As a biguanide derivative, metformin (1,1-dimethylbiguanide hydrochloride) can suppress insulin levels (8), but increase insulin sensitivity of peripheral tissues (9). Accordingly, it has been approved to treat type II diabetes mellitus. Notably, several meta-analyses recently confirmed that metformin therapy could reduce the incidence of cancers, including breast and colorectal cancer, hepatocarcinoma and cancer-related mortality (10-14). Moreover, metformin has been reported to be able to inhibit proliferation and induce apoptosis in triple-negative breast cancer cell lines $(15,16)$. The antitumor properties of metformin have been ascribed to its ability to activate adenosine monophosphate kinase (AMPK), thus, inhibiting the mammalian target of rapamycin (mTOR), a promoter of cell growth and proliferation $(8,17,18)$. Based on these properties, metformin has gained increasing attention as a potential anticancer agent (19). Metformin has been shown to be able to reduce ER expression in endometrial tumors of women with type II diabetes mellitus (20). However, its effect on the expression and function of $\operatorname{ER} \alpha$ in $\mathrm{ER} \alpha$-positive breast cancers regardless of diabetes is currently unclear. Therefore, the objective of the present study was to investigate the anticancer activity of metformin in relation to ER $\alpha$ expression and its signaling pathway in ER $\alpha$-positive MCF-7 and MDA-MB-361 breast cancer cells, and TR MCF-7 breast cancer cells. Notably, it was found that metformin may be more effective at inhibiting ER $\alpha$ signaling by estrogenic 
stimulation compared to tamoxifen for ER $\alpha$-positive breast cancers and that metformin may be an effective therapeutic agent for treating tamoxifen-resistant breast cancer.

\section{Materials and methods}

Cell lines and reagents. Human breast cancer cell lines MCF-7 and MDA-MB-361 were purchased from the American Type Culture Collection (ATCC; Manassas, VA, USA). MCF-7 cells were cultured in RPMI-1640 medium supplemented with $10 \%$ fetal bovine serum (FBS), $100 \mathrm{U} / \mathrm{ml}$ penicillin and $100 \mu \mathrm{g} / \mathrm{ml}$ streptomycin (Gibco, Grand Island, NY, USA). MDA-MB-361 cells were cultured in Leibovitz's L-15 medium (Gibco) supplemented with $20 \% \mathrm{FBS}$ at $37^{\circ} \mathrm{C}$ in a $5 \% \mathrm{CO}_{2}$ humidified incubator. Metformin, 17 $\beta$-estradiol (E2) and 4-hydroxytamoxifen (4-OHT) were purchased from Sigma (St. Louis, MO, USA). Metformin was dissolved in sterile water. E2 and 4-OHT were dissolved in ethanol. They were immediately stored at $-80^{\circ} \mathrm{C}$.

Establishment of the tamoxifen-resistant (TR) MCF-7 cell line. MCF-7 cells were cultured in phenol red-free RPMI-1640 medium supplemented with $10 \%$ charcoal stripped FBS (PAA Laboratories, Morningside, Australia) to deplete estrogen. The tamoxifen-resistant (TR) MCF-7 cell line was established from MCF-7 cells following continuous exposure to $10^{-6} \mathrm{M} 4-\mathrm{OHT}$, an active metabolite of tamoxifen $(21,22)$. Under these conditions, the growth rates of MCF-7 cells were reduced. However, after $\sim 2$ months, cell growth was gradually increased, indicating an acquisition of resistance to growth inhibition of 4-OHT. Designated TR MCF-7 cells were cultured for an additional 4 months in medium containing $4-\mathrm{OHT}$ before characterization studies.

Isolation of RNA and quantitative real-time RT-PCR $(R T-q P C R)$. Total RNA was isolated using the RNeasy Mini kit (Qiagen, Hilden, Germany). For cDNA synthesis, $1 \mu \mathrm{g}$ of total RNA was subjected to reverse transcription-polymerase chain reaction (RT-PCR) assay using CycleScript RT PreMix kit (Bioneer Corporation, Daejeon, Korea). RT-qPCR was performed with Power SYBR-Green PCR Master Mix on an ABI 7300 real-time PCR system (both from Applied Biosystems, Warrington, UK) using the following cycling conditions: $50^{\circ} \mathrm{C}$ for $2 \mathrm{~min}, 95^{\circ} \mathrm{C}$ for $5 \mathrm{~min}$, followed by 40 cycles of $95^{\circ} \mathrm{C}$ for $30 \mathrm{sec}, 55^{\circ} \mathrm{C}$ for $\mathrm{ER} \alpha$ and $\mathrm{pS} 2$ or $60^{\circ} \mathrm{C}$ for cyclin $\mathrm{D} 1$ for $30 \mathrm{sec}, 72^{\circ} \mathrm{C}$ for $30 \mathrm{sec}$. The following primers were used: 5'-AGCACCCAGTGAAGCTACT-3' (ER $\alpha$-forward) and 5'-TAGGGCACACAAACTCCT-3' (ER $\alpha$-reverse); 5'-TATGAATCACTTCTGCAGTGAG-3' (pS2-forward) and 5'-GAGCGTTAGATAACATTTGCC-3' (pS2-reverse); 5'-CGCCCCACCCCTCCAG-3' (cyclin D1-forward) and 5'-CCGCCCAGACCCTCAGACT-3' (cyclin D1-reverse); and 5'-ATCATCCCTGCCTCTACTGG-3' (forward) and 5'-CCCTCCGACGCCTGCTT-CAC-3' (reverse) for GAPDH as internal standard. Cycle threshold values were normalized to those of GAPDH. The relative fold-change was calculated using the $2^{-\Delta \Delta C t}$ method.

Western blot analysis. Protein lysates were prepared with RIPA buffer (20 mM Tris-HCl pH 7.5, 2 mM EDTA, 150 mM
$\mathrm{NaCl}, 1 \mathrm{mM}$ sodium vanadate, $10 \mathrm{mM} \mathrm{NaF}, 2.5 \mathrm{mM}$ sodium pyrophosphate, $1 \%$ sodium deoxycholate, $0.1 \%$ SDS, $1 \%$ NP-40) supplemented with protease inhibitor cocktail (Roche, Mannheim, Germany). Protein concentrations were determined using a BCA protein assay kit (Thermo Scientific, Rockford, IL, USA). Protein samples ( $30 \mu \mathrm{g})$ were resolved by SDS-PAGE and transferred onto polyvinylidene fluoride (PVDF) membranes (Bio-Rad Laboratories). Membranes were blocked with skim milk and incubated with the primary antibodies. Following washing, the membranes were incubated with horseradish peroxidase-conjugated anti-mouse or anti-rabbit secondary antibody and developed with ECL Plus Western Blot Detection System reagent (GE Healthcare Biosciences, Piscataway, NJ, USA). Rabbit anti-ER $\alpha(1: 2,000)$ antibody was purchased from Millipore (Billerica, MA, USA). Mouse anti-cyclin D1 (1:1,000), rabbit anti-TFF1/pS2 $(1: 1,000)$, rabbit anti-phospho-AMPK $\alpha$ (Thr172, 1:1,000) and rabbit anti-AMPK $\alpha(1: 1,000)$ antibodies were purchased from Cell Signaling Technology Inc. (Beverly, MA, USA). Mouse anti-c-Myc $(1: 1,000)$ and rabbit anti-progesterone receptor (PR) (1:1,000) antibodies were purchased from Santa Cruz Biotechnology, Inc. (Dallas, TX, USA). A monoclonal anti- $\beta$-actin $(1: 5,000)$ antibody obtained from Sigma was used to determine protein loading. Protein levels were quantified using ImageJ software (NIH, Bethesda, MD, USA).

Cell proliferation assay. Cells were seeded into 12-well plates at a density of $5 \times 10^{4}$ cells/well $(500 \mu \mathrm{l} / \mathrm{well})$. After incubation for $24 \mathrm{~h}$, the cells were treated with metformin, 4-OHT and E2 in estrogen-depleted RPMI-1640 medium and incubated for an additional $72 \mathrm{~h}$. After that, the cells were trypsinized and counted after staining with trypan blue dye solution using the $\mathrm{TC} 10^{\mathrm{TM}}$ Automated Cell Counter (Bio-Rad Laboratories). The number of viable cells in each well was calculated. Results are presented as relative percentage to the control of each group from three independent experiments in triplicates.

Luciferase assay. The transcriptional activity of ER $\alpha$ was analyzed by luciferase assay using pGL2-3X ERE TATA luc plasmid (Addgene, Cambridge MA, USA). Cells were seeded into 12-well plates and grown to confluency. After co-transfection with pGL2-3X ERE TATA luc and pRL-TK-luc control plasmid (Promega, Madison, WI, USA) using Lipofectamine 2000 reagent (Invitrogen, Carlsbad, CA, USA) for $24 \mathrm{~h}$, the cells were treated with metformin, 4-OHT and E2 in estrogen-depleted RPMI-1640 medium. After an additional incubation for $24 \mathrm{~h}$, luciferase activity was measured using the Dual-Luciferase reporter assay system (Promega) and normalized to pRL-TK-luc activity to correct for differences in transfection efficiency. Results are presented as fold-change relative to the control of each group from three independent experiments in triplicates.

Statistical analysis. Each experiment was performed independently at least three times. Data are presented as mean \pm standard deviation for each experiment. Comparisons between two groups were performed using the Student's t-test. $\mathrm{P}<0.05$ and $\mathrm{P}<0.01$ were considered to indicate a statistically significant result. 


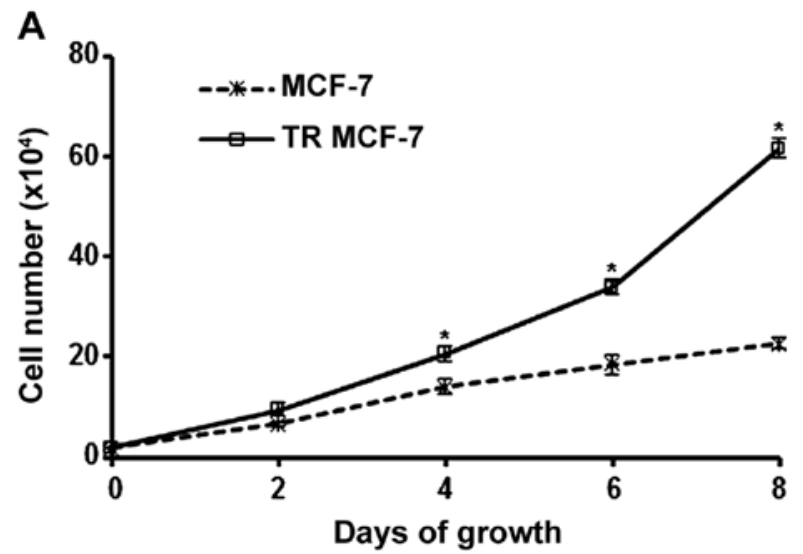

B

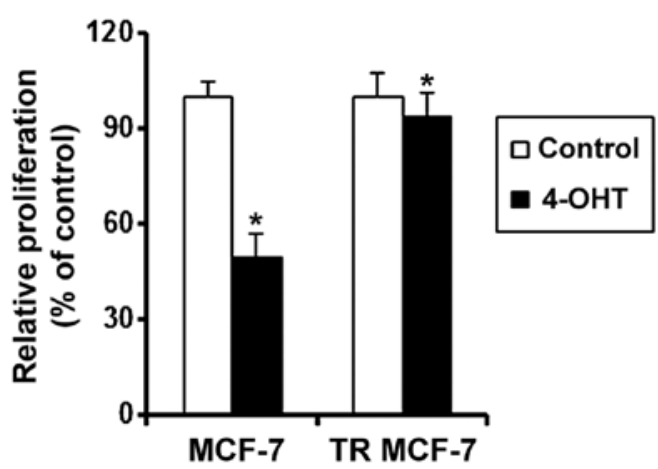

Figure 1. Effect of 4-OHT on the proliferation of MCF-7 and TR MCF-7 cells. (A) MCF-7 and TR MCF-7 cells were seeded into 6-well plates at a density of $2 \times 10^{4}$ cells/well in estrogen-depleted RPMI-1640 medium in the presence of 4-OHT $\left(10^{-6} \mathrm{M}\right)$. Cell number was counted every 2 days by trypan blue staining. Data represent the mean $\pm \mathrm{SD}$ of three independent experiments conducted in triplicates. P-value was calculated compared to the MCF-7 cells; "P $<0.05$. (B) MCF-7 and TR MCF-7 cells were treated with or without 4-OHT in estrogen-depleted RPMI-1640 medium for 5 days. Cell proliferation was determined by trypan blue staining. Data represent the mean $\pm \mathrm{SD}$ of three independent experiments conducted in triplicates. $\mathrm{P}$-value was calculated compared to the untreated Ctrl cells; ${ }^{\mathrm{P}}<0.05$.

\section{Results}

Effect of 4-OHT on the proliferation of MCF-7 and TR MCF-7 cells. To evaluate the acquisition of resistance to the anti-estrogenic action of 4-OHT, we measured the cell proliferation rate of proliferation MCF-7 and the TR MCF-7 cells every 2 days by counting cell numbers. The proliferation rate of proliferation TR MCF-7 cells was significantly higher than that of the MCF-7 cells in the presence of 4-OHT (Fig. 1A). We also determined the proliferation of MCF-7 and TR MCF-7 cells treated with 4-OHT or the control vehicle (Ctrl) for 5 days. The proliferation of the 4-OHT-treated MCF-7 cells was inhibited by $50 \%$ compared to that of the $\mathrm{Ctrl}$ cells. A slight decrease in the proliferation was observed in the 4-OHT-treated TR MCF-7 cells (Fig. 1B).

Metformin inhibits cell proliferation and ER $\alpha$ protein levels in MCF-7 and TR MCF-7 cells. We determined the proliferation of MCF-7 and TR MCF-7 cells treated with metformin at a concentration of 15,20 and $25 \mathrm{mM}$ for $72 \mathrm{~h}$. Compared to the untreated control cells, metformin inhibited the cell proliferation of the MCF-7 and TR MCF-7 cells in a dose-dependent
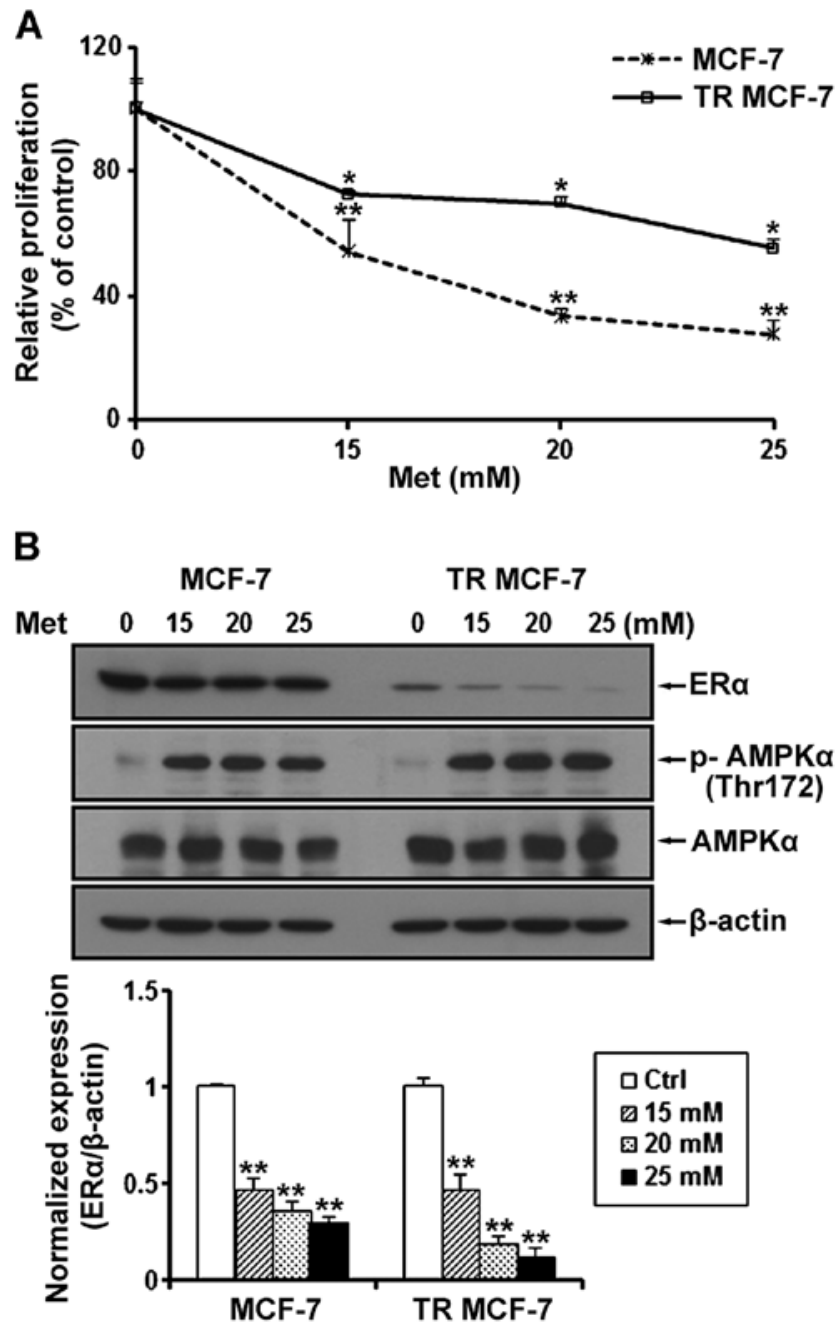

Figure 2. Metformin (Met) inhibits cell proliferation and expression of ER $\alpha$ in MCF-7 and TR MCF-7 cells. (A) Cells were treated with Met at a concentration of 15,20 and $25 \mathrm{mM}$ for $72 \mathrm{~h}$ in each culture medium supplemented with $3 \%$ FBS. Cell proliferation was measured by cell counting using trypan blue staining. (B) The expression levels of ER $\alpha$, phospho(p)-AMPK $\alpha$ (Thr172) and total AMPK $\alpha$ were examined by western blotting. $\beta$-actin was evaluated as a loading control. All data represent the mean \pm SD of three independent experiments conducted in triplicates. P-value was calculated compared to the untreated Ctrl cells; ${ }^{*} \mathrm{P}<0.05$ and ${ }^{* *} \mathrm{P}<0.01$.

manner (Fig. 2A). Compared to the untreated cells, the cell proliferation of the MCF-7 and TR MCF-7 cells was inhibited 70 and $50 \%$, respectively, by $25 \mathrm{mM}$ metformin, indicating that the TR MCF-7 cells were less sensitive at the same concentration of metformin compared to the MCF-7 parental cells for the antiproliferative effect of metformin. Next, we performed western blot analysis to evaluate the effect of metformin on $\mathrm{ER} \alpha$ protein levels. We found that the protein levels of ER $\alpha$ were reduced in a dose-dependent manner by treatment with 15, 20 and $25 \mathrm{mM}$ metformin in both cell lines (Fig. 2B). The concentrations of metformin used in the present study are high, but to focus on the anticancer effects of metformin on TR MCF-7 cells, based on these results, subsequent experiments were carried out using $25 \mathrm{mM}$ metformin. We also determined AMPK $\alpha$ phosphorylation (Thr172) and total AMPK $\alpha$ levels to demonstrate that metformin was present and active during our experiments. 
A

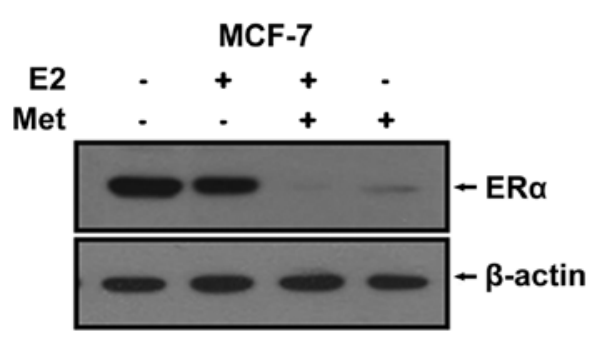

B

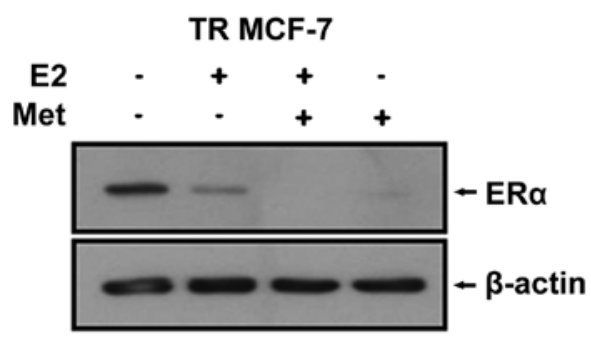

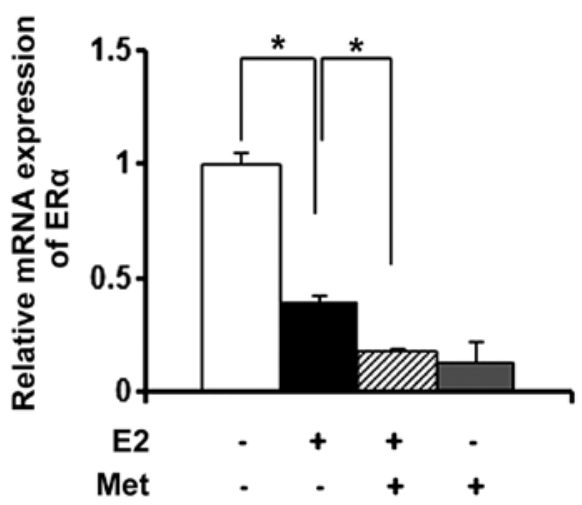

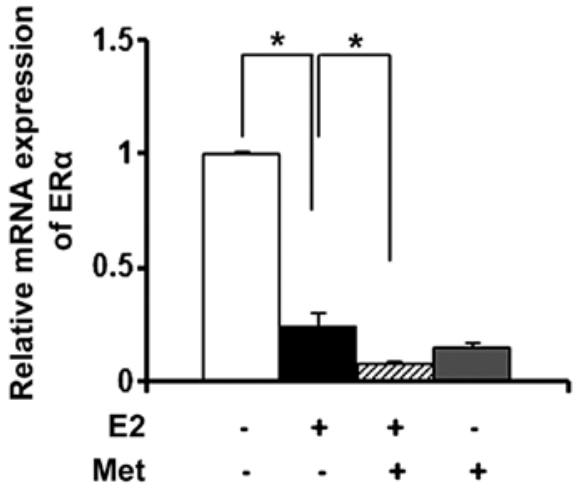

Figure 3. Metformin (Met) inhibits expression of ER $\alpha$ in the MCF-7 and TR MCF-7 cells under E2. (A) MCF-7 and (B) TR MCF-7 cells were treated with Met $(25 \mathrm{mM})$ in the presence of E2 (100 nM) for $48 \mathrm{~h}$ in estrogen-depleted RPMI-1640 medium containing 3\% charcoal stripped FBS. Immunoblots were probed with the anti-ER $\alpha$ antibody (left panels). $\beta$-actin was evaluated as a loading control. ER $\alpha$ mRNA levels were determined by RT-qPCR after treatment of Met and $\mathrm{E} 2$ for $24 \mathrm{~h}$ (right panels). Data represent the mean $\pm \mathrm{SD}$ of three independent experiments conducted in triplicates; ${ }^{*} \mathrm{P}<0.05$.

Metformin inhibits the expression of ER in MCF-7 and $T R$ MCF-7 cells under E2. Since estrogen (E2) is a stimulatory signal for breast cancer development and progression, we treated the MCF-7 and TR MCF-7 cells with metformin in an E2-exposed physiological condition. After treatment with E2, changes in the ER $\alpha$ protein levels were evaluated by western blot analysis. E2 has been reported to be able to rapidly reduce the levels of $E R \alpha$ protein transiently expressed in cells (23). As shown in Fig. 3A and B (left panels), the E2-treated cells had decreased ER $\alpha$ protein levels compared to these levels in the untreated control cells. The protein levels of ER $\alpha$ were decreased more significantly after treatment with metformin. Based on RT-qPCR, we found that metformin also repressed the E2-induced mRNA level of ER $\alpha$ in the MCF-7 cells (0.6-fold decrease compared to E2-treated only cells) and the TR MCF-7 cells (0.7-fold decrease compared to E2-treated only cells) (Fig. 3A and B, right panels).

Metformin inhibits E2-inducible ERE luciferase activity and the expression of ER $\alpha$ target genes in MCF-7 and TR MCF-7 cells. $\mathrm{ER} \alpha$ is known to interact with the estrogen response element (ERE) site of target genes and activate the transcription of regulated genes in response to E2. Therefore, we evaluated the effect of metformin on the transcriptional activity of ER $\alpha$ compared to anti-estrogenic agent 4-OHT. MCF-7 and TR MCF-7 cells were transiently co-transfected with E2-inducible luciferase reporter gene (pGL2-3X ERE TATA luc) and pRL-TK-luc control plasmid. Transfected cells were treated with metformin and 4-OHT under stimulation of E2 or with only metformin for $24 \mathrm{~h}$. As shown in Fig. 4A, E2-induced ERE luciferase activity was inhibited by the treatment of metformin in both the MCF-7 and TR MCF-7 cells. Compared to the E2 only-treated cells, metformin (85\% decrease) was as effective as 4-OHT ( $81 \%$ decrease) in regulating the transcriptional activity of ER $\alpha$ in MCF-7 cells. However, 4-OHT stimulated the ERE luciferase activity in the TR MCF-7 cells. Consequently, we compared the inhibitory effect of metformin and 4-OHT on cellular levels of proteins encoded by E2/ER $\alpha$-regulated genes, including c-Myc, cyclin D1, PR and pS2 in both the MCF-7 (Fig. 4B, left) and the TR MCF-7 (Fig. 4B, right) cells. Metformin inhibited the protein levels of E2-induced c-Myc, cyclin D1, PR and pS2 to a greater extent than 4-OHT. However, 4-OHT exhibited no inhibitory effect on the expression of these target genes in the TR MCF-7 cells. AMPK $\alpha$ phosphorylation (Thr172) and total AMPK $\alpha$ levels were also examined by western blotting. In addition, then we proceeded for RT-qPCR. E2-induced mRNA levels of ER $\alpha$ target genes, cyclin D1 and pS2 were inhibited by the treatment of metformin (Fig. 4C). These results suggest that metformin inhibited ER $\alpha$-mediated transcription levels of its target genes through inhibiting the transcriptional activity of ER $\alpha$ activated by E2 in both the MCF-7 and TR MCF-7 cells.

Metformin inhibits E2-stimulated cell proliferation of the MCF-7 and TR MCF-7 cells. Cell counting using trypan blue staining was performed to compare the antiproliferative effect of metformin and 4-OHT on E2-treated MCF-7 and 
A
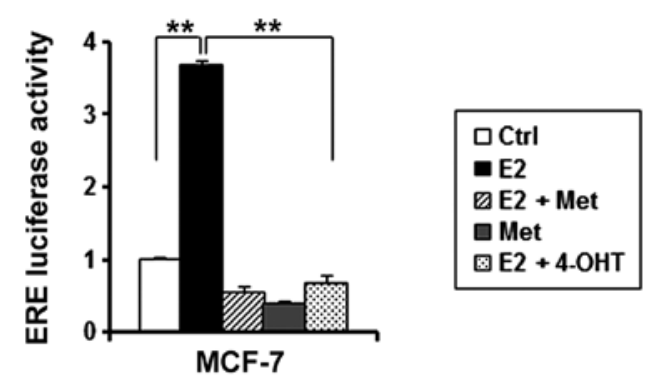

B
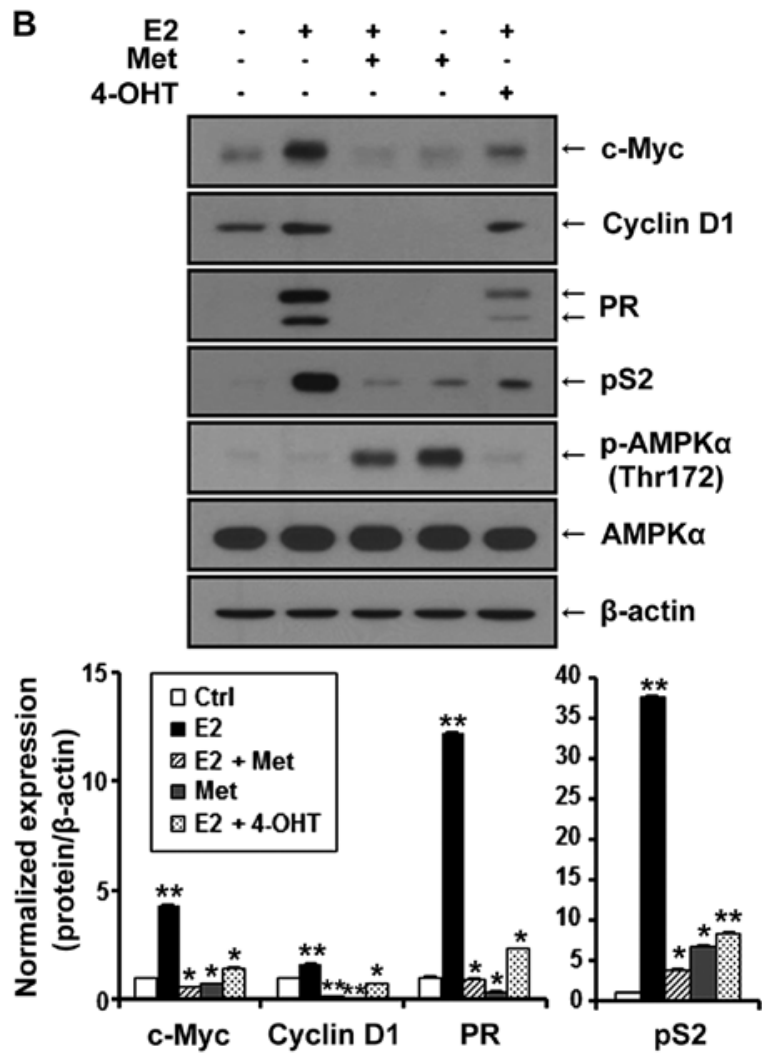

c

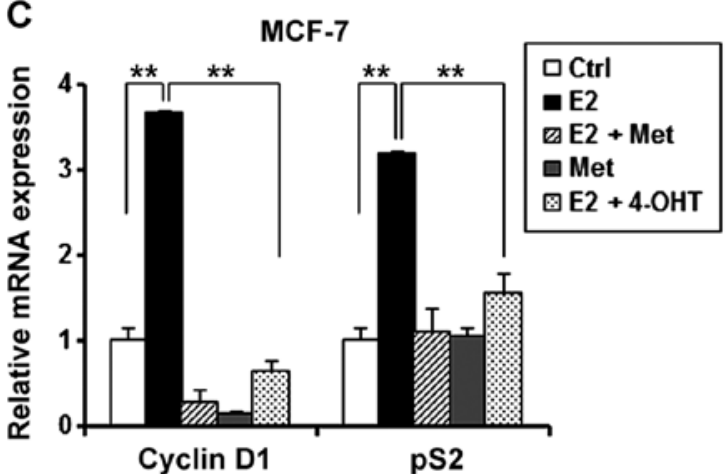

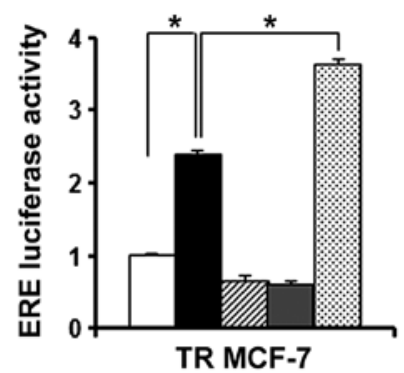

$\begin{array}{rlcccc}\text { E2 } & : & + & + & + & + \\ 4-\mathrm{OHT} & \cdot & \cdot & + & + & +\end{array}$
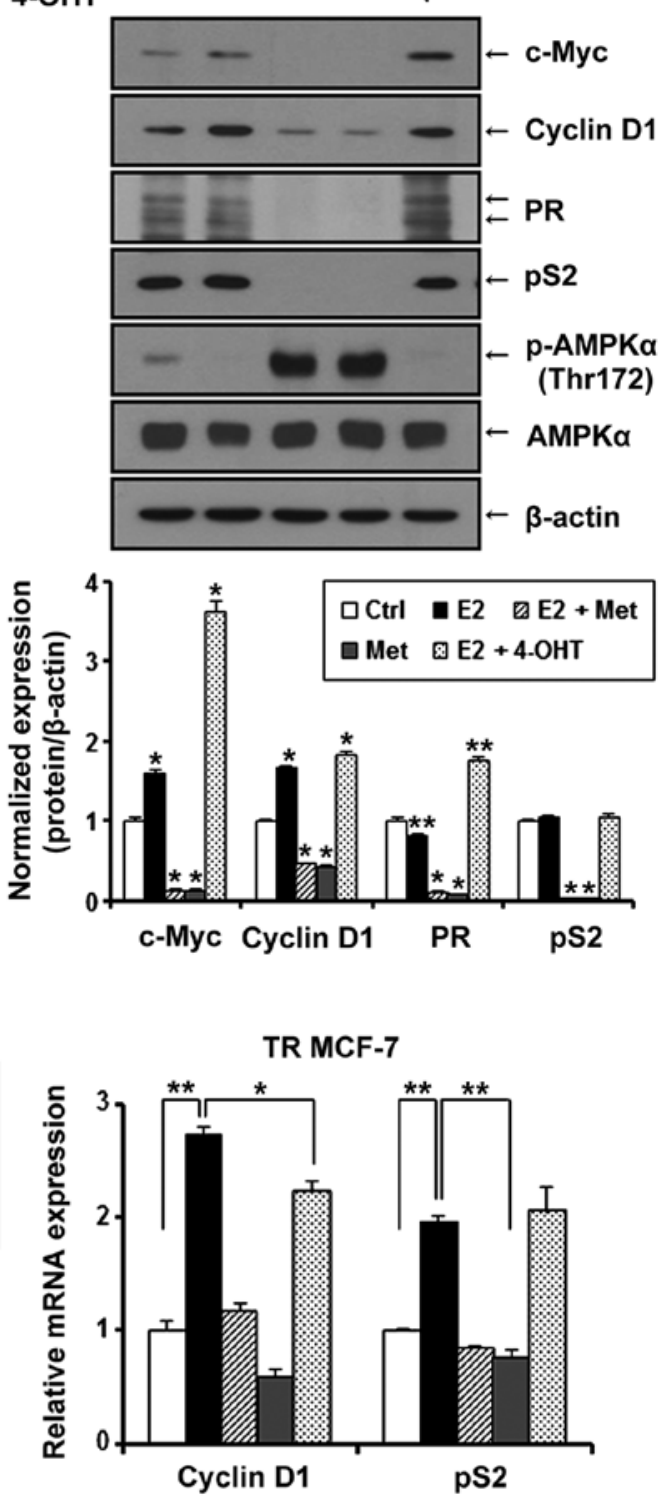

Figure 4. Metformin (Met) inhibits E2-inducible ERE luciferase activity and expression of ER $\alpha$ target genes in MCF-7 and TR MCF-7 cells. (A) Transfected cells were treated with Met $(25 \mathrm{mM})$ and 4-OHT $\left(10^{-6} \mathrm{M}\right)$ in the presence of E2 (100 nM) and ERE luciferase assay was performed. (B) MCF-7 (left) and TR MCF-7 (right) cells were treated with Met and 4-OHT in the presence of E2 for $48 \mathrm{~h}$ in estrogen-depleted RPMI-1640 medium containing $3 \%$ charcoal stripped FBS. The protein levels of c-Myc, cyclin D1, PR, pS2, phospho(p)-AMPK $\alpha$ (Thr172) and total AMPK $\alpha$ were examined by western blotting. $\beta$-actin was evaluated as a loading control. Protein expression levels normalized to $\beta$-actin are presented. Data represent the mean \pm SD of three independent experiments. P-value was calculated compared to untreated Ctrl or E2-treated cells; ${ }^{*} \mathrm{P}<0.05$ and ${ }^{* *} \mathrm{P}<0.01$. (C) RT-qPCR was conducted to assess the mRNA levels of ER $\alpha$ target genes, cyclin $\mathrm{D} 1$ and $\mathrm{pS} 2$. All data represent the mean $\pm \mathrm{SD}$ of three independent experiments conducted in triplicates; ${ }^{*} \mathrm{P}<0.05$ and ${ }^{* *} \mathrm{P}<0.01$.

TR MCF-7 cells. As shown in Fig. 5, metformin inhibited the cell proliferation stimulated by estrogen in both the MCF-7 and TR MCF-7 cells compared to the E2 only-treated cells.
Metformin inhibited cell proliferation of MCF-7 cells (90 vs. $60 \%$ decrease compared to E2 only-treated cells) and TR MCF-7 cells (74 vs. $25 \%$ decrease compared to E2 only- 

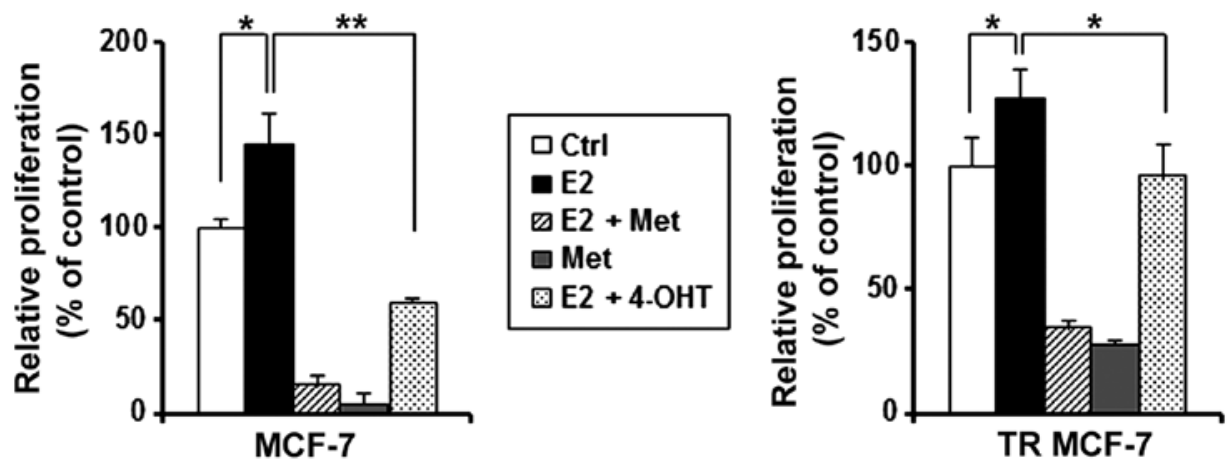

Figure 5. Metformin (Met) inhibits E2-induced cell proliferation in MCF-7 and TR MCF-7 cells. MCF-7 and TR MCF-7 cells were treated with Met (25 mM) and 4-OHT $\left(10^{-6} \mathrm{M}\right)$ in the presence of E2 $(100 \mathrm{nM})$ for $72 \mathrm{~h}$ in estrogen-depleted RPMI-1640 medium containing 3\% charcoal stripped FBS. Cell proliferation assay by cell counting using trypan blue staining was performed. Data represent the mean \pm SD of three independent experiments conducted in triplicates; ${ }^{*} \mathrm{P}<0.05$ and ${ }^{* *} \mathrm{P}<0.01$.

A

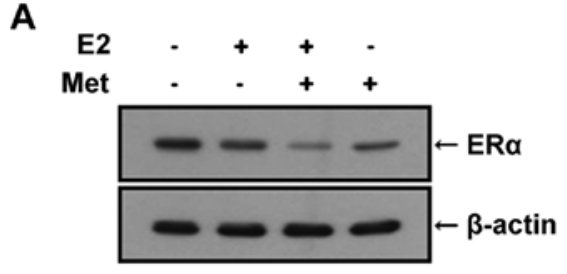

B

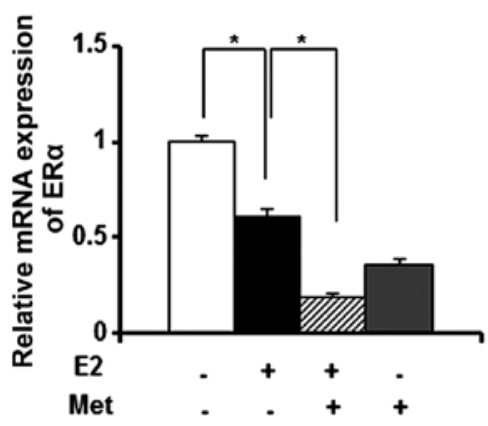

C

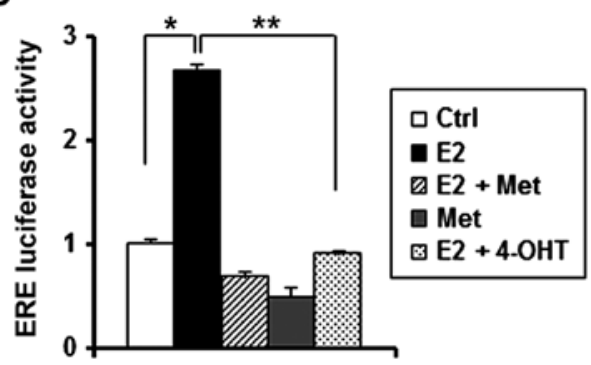

D
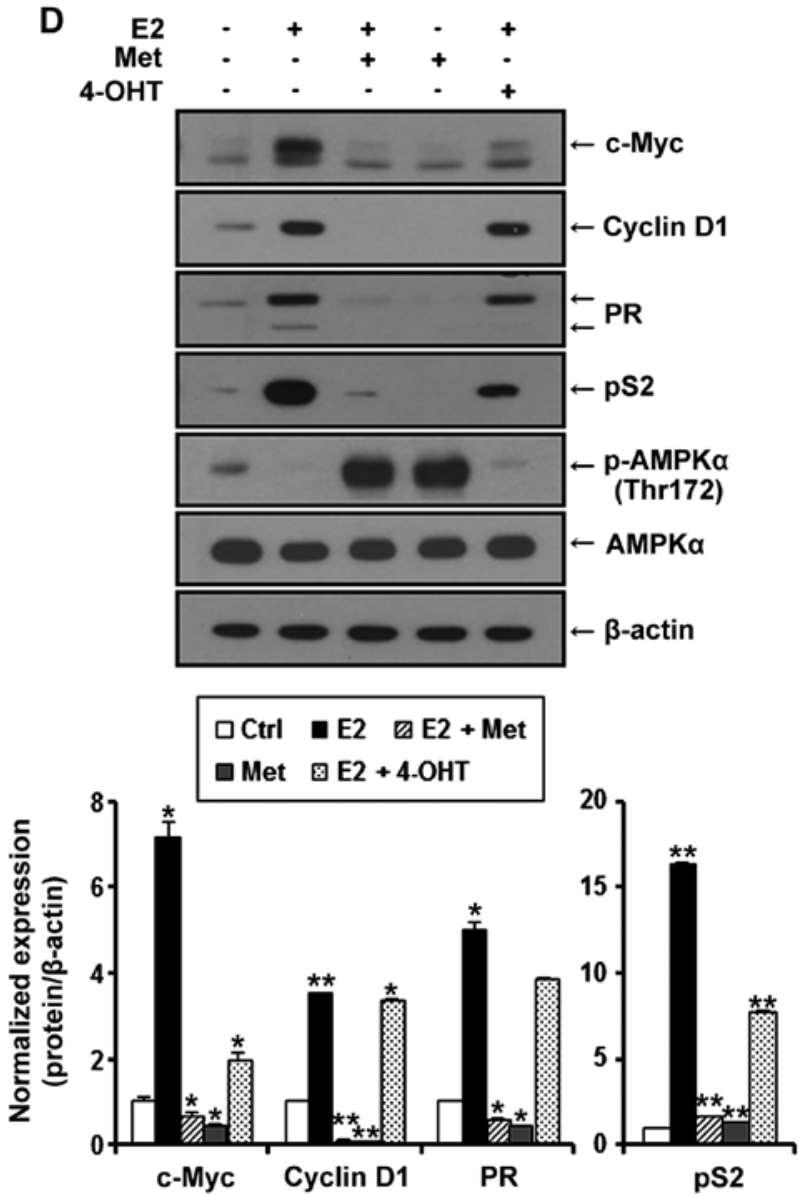

Figure 6. Metformin (Met) inhibits E2-induced expression, function of ER $\alpha$ and cell proliferation in MDA-MB-361 breast cancer cells. (A) The protein levels of ER $\alpha$ were examined by western blotting. $\beta$-actin was evaluated as a loading control. (B) ER $\alpha$ mRNA levels were determined by RT-qPCR. (C) ERE luciferase assay was performed. (D) The protein levels of c-Myc, cyclin D1, PR, pS2, phospho(p)-AMPK $\alpha$ (Thr172) and total AMPK $\alpha$ were examined by western blotting. $\beta$-actin was evaluated as a loading control. Protein expression levels normalized with $\beta$-actin are presented. Data represent the mean \pm SD of three independent experiments. $\mathrm{P}$-value was calculated compared to the untreated Ctrl cells or E2-treated cells; ${ }^{*} \mathrm{P}<0.05$ and ${ }^{* *} \mathrm{P}<0.01$.

treated cells) to a greater extend than 4-OHT. These results suggest that metformin is likely to have an inhibitory effect on the proliferation of MCF-7 and TR MCF-7 cells through the inhibitory function of $E R \alpha$.

Metformin inhibits E2-induced expression, function of ER $\alpha$ and cell proliferation of MDA-MB-361 breast cancer cells.
In general, ER $\alpha$ and HER 2 co-expression in breast cancer may result in the treatment failure of tamoxifen therapy. To properly evaluate the clinical potential of metformin in ER $\alpha$ - and HER2-positive breast cancer (luminal B subtype), we investigated the anticancer effect of metformin using the MDA-MB-361 $\left(\mathrm{ER}^{+} / \mathrm{HER} 2^{+}\right)$cell line. Similar to our results in the MCF-7 and TR MCF-7 cells, metformin reduced the 
E

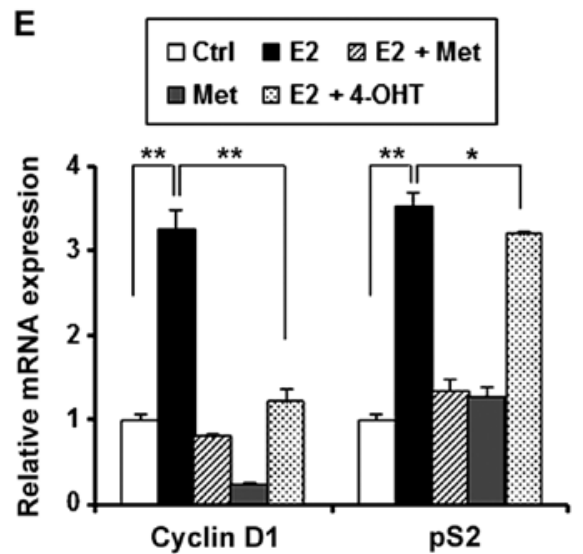

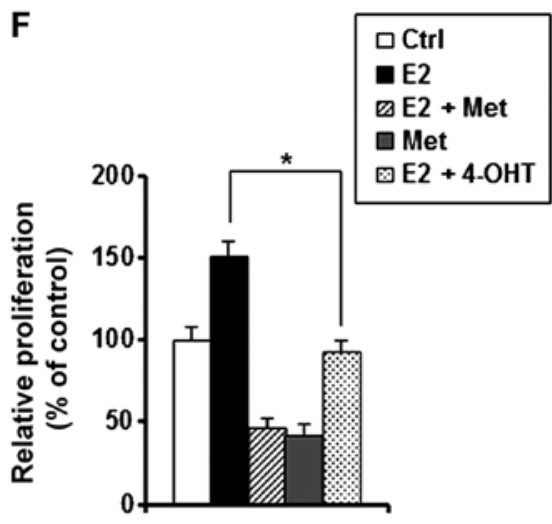

Figure 6. Continued. (E) RT-qPCR was conducted to assess mRNA levels of cyclin D1 and pS2. (F) Cell proliferation was measured by trypan blue staining. All data represent the mean $\pm \mathrm{SD}$ of three independent experiments conducted in triplicates; ${ }^{*} \mathrm{P}<0.05,{ }^{* *} \mathrm{P}<0.01$.

ER $\alpha$ protein (Fig. 6A) and mRNA levels (Fig. 6B). As shown in Fig. 6C, metformin and 4-OHT resulted in a 75 and $67 \%$ decrease in E2-induced ERE luciferase activity, respectively. In addition, E2-induced expression of c-Myc, cyclin D1, PR and pS2 were inhibited by the treatment of metformin. Moreover, we showed AMPK $\alpha$ phosphorylation (Thr172) and total AMPK $\alpha$ levels to demonstrate that metformin was present and active during our experiments (Fig. 6D). Next, we performed RT-qPCR. It was found that E2-induced mRNA levels of cyclin D1 and pS2 were inhibited by the treatment of metformin (Fig. 6E). Metformin resulted in $70 \%$ inhibition of the proliferation of MDA-MB-361 cells compared to cells treated by $\mathrm{E} 2$ only (Fig. 6F).

\section{Discussion}

Estrogen (E2) plays a vital role in the pathogenesis of breast cancer through estrogen receptor $\alpha(\mathrm{ER} \alpha)(24)$. Blocking the $\mathrm{E} 2 / \mathrm{ER} \alpha$ signaling pathway is the first-line therapeutic strategy for patients with ER $\alpha$-positive breast cancer. Although anti-estrogenic therapy using tamoxifen is still an important and major modality to manage ER $\alpha$-positive breast cancer (25), its usefulness is greatly limited by de novo and acquired resistance (26). Therefore, new therapeutic strategies are required to overcome tamoxifen resistance (TR). In the present study, we showed the effectiveness of metformin by targeting ER $\alpha$ using ER $\alpha$-positive as well as tamoxifen-resistant breast cancer cells, thus providing a possible mechanism underlying the anticancer effect of metformin.

Numerous in vitro and in vivo studies have demonstrated that metformin treatment can result in the inhibition of cancer cell growth (27-30). A variety of mechanisms have been invoked to explain the antitumor effect of metformin, including activation of AMPK and inhibition of mTOR $(31,32)$. We focused on research related to the expression and signaling pathway of ER $\alpha$. Our results revealed that metformin inhibited E2-induced expression, ERE luciferase activity, expression of ER $\alpha$ target genes, and cell proliferation of MCF-7 and TR MCF-7 cells. Collectively, our data indicated that the anticancer effect of metformin could be due to the repression of expression and transcriptional function of $\mathrm{ER} \alpha$.
In addition to MCF-7 and TR MCF-7 breast cancer cells, we also assessed the antiproliferative effect of metformin on MDA-MB-361 (ER $\left.\alpha^{+} / \mathrm{HER} 2^{+}\right)$breast cancer cells. HER2 is a transmembrane tyrosine kinase and a member of the human epidermal growth factor receptor (EGFR) family. It leads to the activation of the signaling pathway that promotes cell proliferation, migration, and survival. HER2 amplification and/or overexpression in breast cancer are correlated to poor patient survival or resistance to tamoxifen therapy (33-37). Consistent with our results in the MCF-7 and TR MCF-7 breast cancer cells, metformin also inhibited E2-induced expression and function of ER $\alpha$ as well as the cell proliferation of MDA-MB-361 cells. E2-induced ERE luciferase activity, expression of $\mathrm{ER} \alpha$ target genes, and cell proliferation were also inhibited by tamoxifen in MCF-7 cells, although the effect of tamoxifen was less than that of metformin. Overall, metformin inhibited the ERE luciferase activity, the expression of ER $\alpha$ target genes, and the cell proliferation to a greater extend than 4-OHT in the MCF-7, TR MCF-7 and MDA-MB-361 cells. These effects could be due to the fact that 4-OHT blocked the binding of E2/ER $\alpha$ without suppressing the expression of ER $\alpha$ itself, suggesting that treatment with metformin may be useful for patients with ER $\alpha$-positive breast cancer.

In conclusion, these results suggest that metformin exhibited a superior antiproliferative effect by inhibiting ER $\alpha$ signaling than tamoxifen in ER $\alpha$-positive MCF-7, TR MCF-7 and MDA-MB-361 cells. Currently, there is no alternative standard treatment for tamoxifen-resistant breast tumors except aromatase inhibitors. Therefore, we suggest that metformin may be one of the effective therapeutic agents for treating tamoxifen-resistant breast cancer. Moreover, combination strategies with metformin may be useful for enhancing the treatment efficacy of other cytotoxic chemotherapies or targeted therapies (38). Further experiments including animal studies and clinical trials are warranted.

\section{Acknowledgements}

The present study was supported by a grant (HI14C3405) from the Korea Health Technology R\&D Project through the Korea 
Health Industry Development Institute (KHIDI), funded by the Ministry of Health and Welfare (MOHW), Republic of Korea.

\section{References}

1. Ali S and Coombes RC: Estrogen receptor alpha in human breast cancer: Occurrence and significance. J Mammary Gland Biol Neoplasia 5: 271-281, 2000

2. Hall JM, Couse JF and Korach KS: The multifaceted mechanisms of estradiol and estrogen receptor signaling. J Biol Chem 276: 36869-36872, 2001

3. Couse JF and Korach KS: Estrogen receptor null mice: What have we learned and where will they lead us? Endocr Rev 20 : 358-417, 1999.

4. Colditz GA: Relationship between estrogen levels, use of hormone replacement therapy, and breast cancer. J Natl Cancer Inst 90: 814-823, 1998.

5. Hankinson SE, Colditz GA and Willett WC: Towards an integrated model for breast cancer etiology: The lifelong interplay of genes, lifestyle, and hormones. Breast Cancer Res 6: 213-218, 2004.

6. Uray IP and Brown PH: Chemoprevention of hormone receptornegative breast cancer: New approaches needed. In: Clinical Cancer Prevention. Springer, pp147-162, 2011.

7. Osborne CK: Tamoxifen in the treatment of breast cancer. N Engl J Med 339: 1609-1618, 1998.

8. Shaw RJ, Lamia KA, Vasquez D, Koo SH, Bardeesy N, Depinho RA, Montminy M and Cantley LC: The kinase LKB1 mediates glucose homeostasis in liver and therapeutic effects of metformin. Science 310: 1642-1646, 2005.

9. Bailey CJ and Turner RC: Metformin. N Engl J Med 334: 574-579, 1996.

10. Bowker SL, Majumdar SR, Veugelers P and Johnson JA: Increased cancer-related mortality for patients with type 2 diabetes who use sulfonylureas or insulin. Diabetes Care 29: 254-258, 2006.

11. Evans JM, Donnelly LA, Emslie-Smith AM, Alessi DR and Morris AD: Metformin and reduced risk of cancer in diabetic patients. BMJ 330: 1304-1305, 2005.

12. Decensi A, Puntoni M, Goodwin P, Cazzaniga M, Gennari A, Bonanni B and Gandini S: Metformin and cancer risk in diabetic patients: A systematic review and meta-analysis. Cancer Prev Res 3: 1451-1461, 2010.

13. Bosco JLF, Antonsen S, Sørensen HT, Pedersen L and Lash TL: Metformin and incident breast cancer among diabetic women: A population-based case-control study in Denmark. Cancer Epidemiol Biomarkers Prev 20: 101-111, 2011.

14. Beck E and Scheen AJ: Metformin, an antidiabetic molecule with anti-cancer properties. Rev Med Liege 68: 444-449, 2013 (In French).

15. Liu B, Fan Z, Edgerton SM, Deng XS, Alimova IN, Lind SE and Thor AD: Metformin induces unique biological and molecular responses in triple negative breast cancer cells. Cell Cycle 8: 2031-2040, 2009.

16. Jiralerspong S, Gonzalez-Angulo AM and Hung M-C: Expanding the arsenal: Metformin for the treatment of triple-negative breast cancer? Cell Cycle 8: 2681-2684, 2009.

17. Marx J: Medicine. Cancer-suppressing enzyme adds a link to type 2 diabetes. Science 310: 1259-1259, 2005.

18. Goodwin PJ, Pritchard KI, Ennis M, Clemons M, Graham M and Fantus IG: Insulin-lowering effects of metformin in women with early breast cancer. Clin Breast Cancer 8: 501-505, 2008.

19. Dowling RJ, Goodwin PJ and Stambolic V: Understanding the benefit of metformin use in cancer treatment. BMC Med 9: 33 , 2011.

20. Markowska A, Pawałowska M, Filas V, Korski K, Gryboś M, Sajdak S, Olejek A, Bednarek W, Spiewankiewicz B, Lubin J, et al: Does Metformin affect ER, PR, IGF-1R, $\beta$-catenin and PAX-2 expression in women with diabetes mellitus and endometrial cancer? Diabetol Metab Syndr 5: 76, 2013.
21. Yoo YA,Kim YH,Kim JS and Seo JH: The functionalimplications of Akt activity and TGF-beta signaling in tamoxifen-resistant breast cancer. Biochim Biophys Acta 1783: 438-447, 2008.

22. Knowlden JM, Hutcheson IR, Jones HE, Madden T, Gee JM, Harper ME, Barrow D, Wakeling AE and Nicholson RI: Elevated levels of epidermal growth factor receptor/c-erbB2 heterodimers mediate an autocrine growth regulatory pathway in tamoxifen-resistant MCF-7 cells. Endocrinology 144: 1032-1044, 2003.

23. Dauvois S, Danielian PS, White R and Parker MG: Antiestrogen ICI 164,384 reduces cellular estrogen receptor content by increasing its turnover. Proc Natl Acad Sci USA 89: 4037-4041, 1992.

24. Clark GM, Osborne CK and McGuire WL: Correlations between estrogen receptor, progesterone receptor, and patient characteristics in human breast cancer. J Clin Oncol 2: 1102-1109, 1984.

25. Honig SF: Tamoxifen for the reduction in the incidence of breast cancer in women at high risk for breast cancer. Ann NY Acad Sci 949: 345-348, 2001

26. Osborne CK and Schiff R: Mechanisms of endocrine resistance in breast cancer. Annu Rev Med 62: 233-247, 2011.

27. Zakikhani M, Dowling R, Fantus IG, Sonenberg N and Pollak M: Metformin is an AMP kinase-dependent growth inhibitor for breast cancer cells. Cancer Res 66: 10269-10273, 2006.

28. Dowling RJ, Zakikhani M, Fantus IG, Pollak M and Sonenberg N: Metformin inhibits mammalian target of rapamycin-dependent translation initiation in breast cancer cells. Cancer Res 67: 10804-10812, 2007.

29. Ben Sahra I, Laurent K, Loubat A, Giorgetti-Peraldi S, Colosetti P, Auberger P, Tanti JF, Le Marchand-Brustel Y and Bost F: The antidiabetic drug metformin exerts an antitumoral effect in vitro and in vivo through a decrease of cyclin D1 level. Oncogene 27: 3576-3586, 2008.

30. Buzzai M, Jones RG, Amaravadi RK, Lum JJ, DeBerardinis RJ, Zhao F, Viollet B and Thompson CB: Systemic treatment with the antidiabetic drug metformin selectively impairs p53-deficient tumor cell growth. Cancer Res 67: 6745-6752, 2007.

31. Gonzalez-Angulo AM and Meric-Bernstam F: Metformin: A therapeutic opportunity in breast cancer. Clin Cancer Res 16: 1695-1700, 2010

32. Zhou G, Myers R, Li Y, Chen Y, Shen X, Fenyk-Melody J, Wu M, Ventre J, Doebber T, Fujii N, et al: Role of AMP-activated protein kinase in mechanism of metformin action. J Clin Invest 108: 1167-1174, 2001

33. Gullick WJ, Berger MS, Bennett PL, Rothbard JB and Waterfield MD: Expression of the c-erbB-2 protein in normal and transformed cells. Int J Cancer 40: 246-254, 1987.

34. King CR, Kraus MH and Aaronson SA: Amplification of a novel v-erbB-related gene in a human mammary carcinoma. Science 229: 974-976, 1985 .

35. Riese DJ II, van Raaij TM, Plowman GD, Andrews GC and Stern DF: The cellular response to neuregulins is governed by complex interactions of the erbB receptor family. Mol Cell Biol 15: 5770-5776, 1995.

36. Slamon DJ, Clark GM, Wong SG, Levin WJ, Ullrich A and McGuire WL: Human breast cancer: Correlation of relapse and survival with amplification of the HER-2/neu oncogene. Science 235: 177-182, 1987.

37. Ross JS and Fletcher JA: The HER-2/neu oncogene in breast cancer: Prognostic factor, predictive factor, and target for therapy. Stem Cells 16: 413-428, 1998.

38. Kim J, Lee J, Kim C, Choi J and Kim A: Anti-cancer effect of metformin by suppressing signaling pathway of HER 2 and HER3 in tamoxifen-resistant breast cancer cells. Tumour Biol: Nov 18, 2015 (Epub ahead of print). 